\title{
Acute Pressor Actions of Ouabain Do Not Enhance the Actions of Phenylephrine or Norepinephrine in Anesthetized Rats
}

\author{
Louis A. Barker, *Luciana V. Rossoni, and *Dalton V. Vassallo \\ Department of Pharmacology, Louisiana State University Health Sciences Center, New Orleans, Louisiana, U.S.A.; \\ and $*$ Department of Physiological Sciences, Biomedical Center, Federal University of Espirito Santo, Vitoria, \\ Espirito Santo, Brazil
}

\begin{abstract}
Summary: The inhibition of high-affinity isoforms of the $\mathrm{Na}^{+}, \mathrm{K}^{+}$-ATPase by nanomolar levels of ouabain has been proposed to enhance the actions of vasoconstrictor agents that act via a $\mathrm{Ca}^{+2}$-dependent mechanism. The present study tested this hypothesis by evaluating the effects of ouabain (6 and 18 $\mu \mathrm{g} / \mathrm{kg}$, i.v.) on the vasopressor actions of phenylephrine and norepinephrine in anesthetized, reflex-blocked rats. In separate groups of animals, dose-response curves for increases in diastolic pressure produced by phenylephrine were generated after the administration of saline (control), ouabain $(18 \mu \mathrm{g} / \mathrm{kg}$ ), L-omega- $N$-nitro arginine methyl ester (L-NAME, $3 \mu \mathrm{mol} / \mathrm{kg}$ ) and angiotensin II $(15 \mathrm{ng} / \mathrm{kg}$ per min). Treatment with ouabain $(18 \mu \mathrm{g} / \mathrm{kg})$ produced an increase in diastolic pressure of $19 \pm 3 \mathrm{~mm} \mathrm{Hg}$ but did not significantly alter the potency or maximal response produced by phenylephrine. In contrast, treatment with angiotensin II and L-NAME, agents known to enhance the actions of $\alpha$-adrenoceptor agonists, increased the potency of phenylephrine. In animals in which the pressor actions of norepinephrine were evaluated before and after the administration of ouabain $(6 \mu \mathrm{g} / \mathrm{kg})$, ouabain did not alter the pressor response to norepinephrine. Blockade of $\alpha$-adrenoceptors with phentolamine was found to attenuate as well as partially reverse the increase in diastolic pressure produced by ouabain. These observations suggest that ouabain produces a pressor response by actions on sympathetic nerve endings as well as on vascular smooth muscle and that these actions do not alter the sensitivity to phenylephrine or norepinephrine. Key Words: Ouabain-PhenylephrineNorepinephrine-L-NAME-Angiotensin II.
\end{abstract}

Endogenous ouabain (ouabain or a closely related isomer) is thought to play a role in some forms of hypertension $(1,2)$. Short-term and long-term administration of ouabain produces an increase in systemic arterial blood pressure (3-7). In normal human volunteers (6) and rats (7) the short-term administration of ouabain in the range of $10-30 \mathrm{nmol} / \mathrm{kg}$, i.v., produces a pressor response that is peripheral in origin. Long-term treatment with ouabain
Received October 10, 2000; revision accepted December 13, 2000. Address correspondence and reprint requests to Dr. L. A. Barker at Department of Pharmacology, Louisiana State University Health Sci- ences Center/School of Dentistry, 1100 Florida Avenue, New Orleans, LA 70119, U.S.A. E-mail: lbarke@1sumc.edu 
in rats produces a hypertension that appears to be mainly of central origin (8). The primary site of action of ouabain is generally assumed to be the $\alpha$-subunit of $\mathrm{Na}^{+}, \mathrm{K}^{+}$ATPase, which is a heterotrimer composed of $\alpha-, \beta$-and $\gamma$-subunits that exist in isoforms (9-11). In the rat, but not other species, the $\alpha$ subunit isoforms show marked differences in affinity for ouabain. The $\alpha_{1}, \alpha_{2}$, and $\alpha_{3}$ isoforms show low, high and very high affinities for ouabain that are in the ranges of 50-100 $\mu M, 30 \mathrm{n} M$, and $1 \mathrm{n} M$, respectively (12-14).

Rat vascular tissue contains $\alpha_{1}, \alpha_{2}$, and $\alpha_{3}$ subunits (15). The $\alpha_{2}$ and $\alpha_{3}$ isoforms of the sodium pump appear to be preferentially localized on the plasma membranes in regions that are in anatomic communication with the sarcoplasmic and endoplasmic reticulum $(16,17)$. The inhibition of the high-affinity isoforms of the sodium pump by nanomolar concentrations of ouabain at these sites (18) can produce an increase in the intracellular store of $\mathrm{Ca}^{+2}$ that is proposed to be readily available for release on stimulation (19) and to result in an amplification of the effect of agonists that cause a $\mathrm{Ca}^{+2}$-dependent contraction $(1,19)$. Ouabain alone produces a peripheral vasoconstriction in humans at doses between $10-30 \mathrm{nmol} / \mathrm{kg}$, i.v. (6). A subpressor dose of ouabain, $0.1 \mathrm{mg} / \mathrm{m}^{2}$, i.v., was shown to enhance the ability of a single dose of norepinephrine to increase mean arterial pressure (20). In vitro, nanomolar concentrations of ouabain have been shown to enhance caffeine-induced contractures and to increase phenylephrine's ability to potentiate caffeine-induced contractions of rat isolated vascular preparations (21). Collectively, these observations support the hypothesis that nanomolar concentrations of ouabain, which should selectively interact with the high-affinity $\alpha_{2}$ and $\alpha_{3}$ isoforms of $\mathrm{Na}^{+}, \mathrm{K}^{+}$-ATPase, enhance the actions of vasoconstrictor agents. However, the effects of nanomolar doses of ouabain on a full-dose response curve for a pressor agent have not been reported. This type of analysis allows an evaluation of potential effects of ouabain on potency $\left(\mathrm{ED}_{50}\right.$, dose producing one-half maximal response) and the maximal response.

The present studies were undertaken to evaluate the hypothesis that relatively low doses of ouabain ( 6 and 18 $\mu \mathrm{g} / \mathrm{kg}$, which correspond to approximately 10 and 30 $\mathrm{nmol} / \mathrm{kg}$ ) produce an enhancement of the vasoconstrictor actions of $\alpha$-adrenoceptor agonists. Our results show that in the reflex-blocked anesthetized rat, ouabain increases diastolic pressure by phentolamine-sensitive and -insensitive mechanisms. At the doses used, ouabain induced increases in diastolic pressure but did not alter the doseresponse curve for phenylephrine or the responsiveness to submaximal doses of norepinephrine.

\section{METHODS}

\section{Animals, experimental groups, and experimental protocols}

Male Wistar rats, 250-325 g, were used. All experiments were conducted in compliance with the guidelines for biomedical research as stated by the Brazilian Societies of Experimental Biology. On the day of the experiment, the animals were anesthetized with urethane, 1.2 $\mathrm{g} / \mathrm{kg}$, i.p. After the onset of anesthesia, cannulae were placed in the left common carotid and right and/or left femoral veins for recording blood pressure and pulse rate and drug administration, respectively. A 10-min stabilization period was observed before administration of any drugs. Before any treatments, all animals received hexamethonium, $10 \mathrm{mg} / \mathrm{kg}$; propranolol, $1 \mathrm{mg} / \mathrm{kg}$; and atropine, $1 \mathrm{mg} / \mathrm{kg}$, in that order, to block autonomic reflexes. Five to $10 \mathrm{~min}$ after the administration of atropine, a short-term treatment or saline was administered. The following treatment groups were employed: control (saline, $0.1 \mathrm{ml} / \mathrm{kg}$ ), ouabain $(18 \mu \mathrm{g} / \mathrm{kg}$, which is $31 \mathrm{nmol} / \mathrm{kg})$, L-NAME $(3 \mu \mathrm{mol} / \mathrm{kg})$, and angiotensin II $(15 \mathrm{ng} / \mathrm{kg}$ per min, infused at a rate of $22 \mu \mathrm{l} / \mathrm{min}$ ). Dose-response curves to phenylephrine $(0.1-100 \mu \mathrm{g} / \mathrm{kg})$ were initiated 10-15 min after the administration of saline, 30 min after pretreatment with L-NAME, 15 min after angiotensin, or 60 min after pretreatment with ouabain, times at which the effects of the treatment agents on blood pressure were in a plateau. Studies on L-NAME and angiotensin II were included as positive controls because it is known that these agents can enhance the actions of $\alpha$-adrenoceptor agonists (22-24). To permit an evaluation of the effectiveness of the reflex blockade, dose-response curves to phenylephrine were generated in anesthetized rats in the absence of the blocking drugs and the changes in diastolic pressure and heart rate were measured.

In a separate group of animals, the effects of ouabain, $6 \mu \mathrm{g} / \mathrm{kg}$, on the pressor effects of submaximal doses of norepinephrine $(01,0.3$, and $1 \mu \mathrm{g} / \mathrm{kg})$ were evaluated. These doses of norepinephrine roughly correspond to doses of phenylephrine that produce from $10 \%$ to $50 \%$ of the maximal response. In these animals the effects of norepinephrine on diastolic pressure before the administration of ouabain and at 60-75 min after the administration of ouabain were measured. This experimental design and dose of ouabain were used to more closely mimic human studies on the effect of ouabain on norepinephrine (20).

In other experiments the effects of the nonselective $\alpha$-adrenoceptor antagonist phentolamine, $3 \mathrm{mg} / \mathrm{kg}$, on the pressor response to ouabain $(18 \mu \mathrm{g} / \mathrm{kg})$ were determined. In three pilot experiments it was determined that 
this dose of phentolamine produced a 30 -fold rightward shift in the dose-response curve for phenylephrine at 3060 min after administration, which reversed to an approximately 20 -fold dextral shift by $90 \mathrm{~min}$ after administration. The ability of phentolamine to prevent as well as reverse the pressor response to ouabain was evaluated. In the former experiments, phentolamine was administered 5-10 min after atropine and $10 \mathrm{~min}$ before ouabain, at a time when the depressor effects of phentolamine had stabilized. The diastolic pressure at $60 \mathrm{~min}$ after the administration of ouabain was used as the measure of the response to ouabain. In the reversal experiments, phentolamine was administered $60 \mathrm{~min}$ after ouabain, at a time when the pressor effects of ouabain had reached a plateau. Except as noted above, all drugs were administered by the intravenous route in saline at a volume of 0.1 $\mathrm{ml} / \mathrm{kg}$, followed by a $0.1 \mathrm{ml}$ flush.

\section{Blood pressure and pulse rate recording}

Blood pressure was measured using a pressure transducer (model 1050BR, UFI, Inc., Morro Bay, CA, U.S.A.) and recorded using an interface and software for computer data acquisition (model MP100A, BIOPAC Systems, Inc., Santa Barbara, CA, U.S.A.). Pulse rates were determined from the intra-beat intervals.

\section{Dose-response curves}

Phenylephrine was administered in doses of 0.1-100 $\mu \mathrm{g} / \mathrm{kg}$ at approximately half-log intervals sequentially in an ascending order. The logarithm of the dose and the increase in the diastolic pressure produced by phenylephrine were used as the dose and response metameters (25). The increment was measured from the base-line diastolic pressure before the dose of phenylephrine to the peak of the increase caused by phenylephrine.

\section{Statistical analysis}

The metameters for dose and response data were used in iterative nonlinear regression analyses to estimate the unknown parameters, $\mathrm{E}_{\max }, \log \mathrm{ED}_{50}$, and the slope factor that define the dose-response curve as given by the following equation:

$$
\mathrm{E}=\frac{\mathrm{E}_{\max }}{\left(1+\left(10^{\mathrm{x}} / 10^{\mathrm{B}}\right)^{n}\right)},
$$

where $\mathrm{E}$ is the observed change in diastolic pressure; $\mathrm{E}_{\max }$ is the estimated maximal change in diastolic pressure; $\mathrm{X}$ is the logarithm of the dose of phenylephrine; $\mathrm{B}$, the index of potency, is the logarithm of the dose producing one half $\mathrm{E}_{\max }\left(\log \mathrm{ED}_{50}\right)$; and $\mathrm{n}$ is a curve-fitting parameter that defines the steepness of the dose-response curve.

Data are presented as mean \pm SEM. One-way ANOVA was carried out on the individual dose-response parameters $\left(\mathrm{E}_{\max }, \log \mathrm{ED}_{50}\right.$, and $\left.\mathrm{n}\right)$ to determine if treatments had an effect. Significance was determined by Dunnet's post hoc test for multiple comparisons to the respective control values. The effects of phentolamine on the pressor actions of ouabain and the effects of ouabain on the pressor effects of norepinephrine were evaluated by a repeated measures one-way ANOVA and Tukey's post hoc test for multiple comparisons was used to determine significance. In some cases, Student $t$ tests were used. A p value of $<0.05$ was considered significant. Dose-response and statistical analyses were performed using the program Prism3 (GraphPad Software, San Diego, CA, U.S.A.).

\section{Drugs}

Angiotensin II, diacetate tetrahydrate, atropine sulfate, hexamethonium dichloride, L-NAME hydrochloride, norepinephrine bitartrate, ouabain octahydrate, phenylephrine hydrochloride, phentolamine hydrochloride, D,L-propranolol hydrochloride, and urethane were obtained from Sigma Chemical Co. (St. Louis, MO, U.S.A.) All drugs except norepinephrine were dissolved in $0.9 \%$ saline and doses refer to the salt form used. Norepinephrine was dissolved in $0.1 \%$ sodium metabisulfate in saline and fresh solutions were prepared for each experiment.

\section{RESULTS}

Table 1 shows the values for diastolic pressure of the experimental groups before and after reflex blockade and

TABLE 1.

Diastolic pressure before and after reflex blockade $(R B)$ and after treatment ${ }^{a}$

\begin{tabular}{lcccc}
\hline $\begin{array}{l}\text { Treatment } \\
\text { group }\end{array}$ & ${\text { Before } \mathrm{RB}^{b}}^{b}$ & $\begin{array}{c}\text { Diastolic pressure } \\
\text { after RB (mmHg) }\end{array}$ & $\begin{array}{c}\text { After } \\
\text { treatment }\end{array}$ & No. \\
\hline Control & $60 \pm 4$ & $48 \pm 2$ & $50 \pm 3$ & 6 \\
Ouabain & $64 \pm 9$ & $52 \pm 2$ & $71 \pm 3^{b, c}$ & 6 \\
L-NAME 3.0 & $60 \pm 6$ & $51 \pm 2$ & $87 \pm 10^{b, c}$ & 5 \\
Angiotensin II & $57 \pm 5$ & $51 \pm 4$ & $53 \pm 4$ & 6 \\
\hline
\end{tabular}

${ }^{a}$ Values are mean \pm SEM for number of animals. Values are rounded to nearest whole number. Treatment refers to the drug administered after reflex blockade.

${ }^{b}$ Within column, significantly different from control value, $\mathrm{p}<0.05$, one-way ANOVA followed by a Dunnet's post hoc test.

${ }^{c}$ Significantly different from respective post-RB value, $\mathrm{p}<0.05$, paired $t$ test. 
after treatments. There were no significant differences among the groups for diastolic pressures before or after reflex blockade. Relative to their values after reflex blockade, both ouabain and L-NAME produced significant increases in diastolic pressure $(\mathrm{p}<0.05$, paired $t$ test). The sustained pressor effect of ouabain was slow in onset. Immediately after the injection of ouabain there was a small increase in pressure that returned to baseline values within $5 \mathrm{~min}$. Approximately $40 \mathrm{~min}$ after ouabain injection, the diastolic pressure slowly increased to a plateau value by $60 \mathrm{~min}$ that was sustained for at least an additional hour (Rossoni LV and Vassallo DV, unpublished observations). All observations on the pressor actions of phenylephrine and norepinephrine were made within this time period. Saline treatment and angiotensin II at $15 \mathrm{ng} / \mathrm{kg}$ per min had no significant effects on diastolic blood pressure ( $\mathrm{p}>0.05$, paired $t$ tests).
Figure 1 shows dose-response curves for phenylephrine-induced changes in diastolic pressure and pulse rate in the control animals with and without reflex blockade and in ouabain-treated rats with reflex blockade. These results show that the reflex blockade produced an inhibition of $87 \%-100 \%$ of the baroreceptor reflex-induced decrease in pulse rate evoked by the pressor actions of phenylephrine. In the presence of reflex blockade there were no significant differences in the dose-response curves for changes in pulse rate for the control and ouabain reflex-blocked groups. Similarly, there also were no changes in pulse rate after norepinephrine administration to reflex-blocked animals before and after the administration of ouabain (data not shown). Figure 2 shows the absolute diastolic pressures before and after the administration of phenylephrine in control and ouabain-treated animals. Here it is seen that ouabain at $18 \mu \mathrm{g} / \mathrm{kg}$, i.v.,

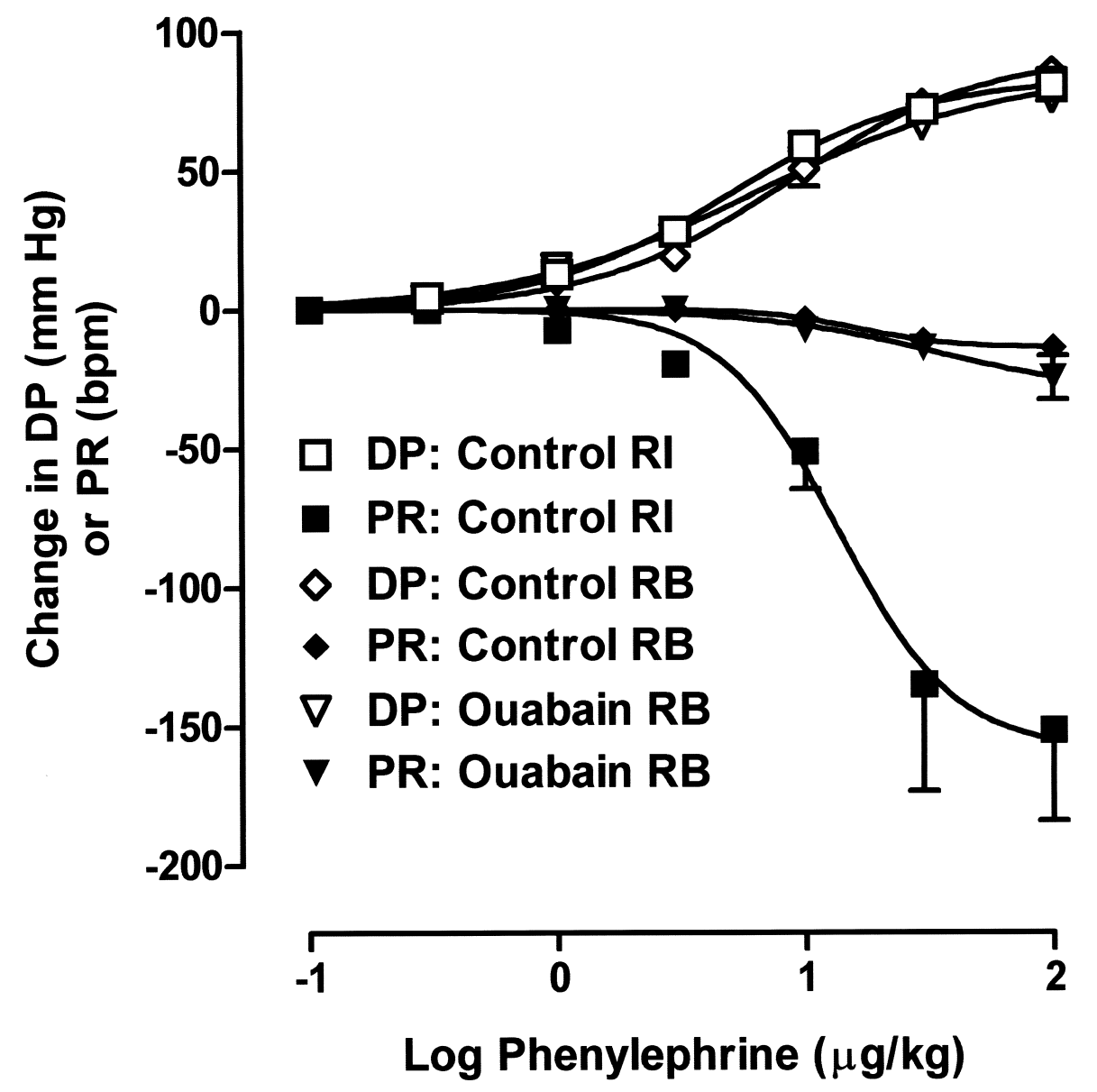

FIG. 1. Dose-response curve for the effects of phenylephrine on changes in diastolic pressure (DP) and pulse rate (PR) in control rats with reflexes intact $(\mathrm{RI})$ and with reflexes blocked (RB) and in rats treated with ouabain $(18 \mu \mathrm{g} / \mathrm{kg})$ after reflex blockade. The open symbols depict changes in diastolic pressure and the corresponding closed symbols depict changes in pulse rate. Symbols and bars show mean \pm SEM ( $n=6$ per group). Where no bars are seen, the value of the SEM is within the area covered by the symbol. The basal values for pulse rates were control RI, $315 \pm 19$; control RB, $298 \pm 10$; and ouabain RB, $284 \pm 3$ beats $/ \mathrm{min}$. 


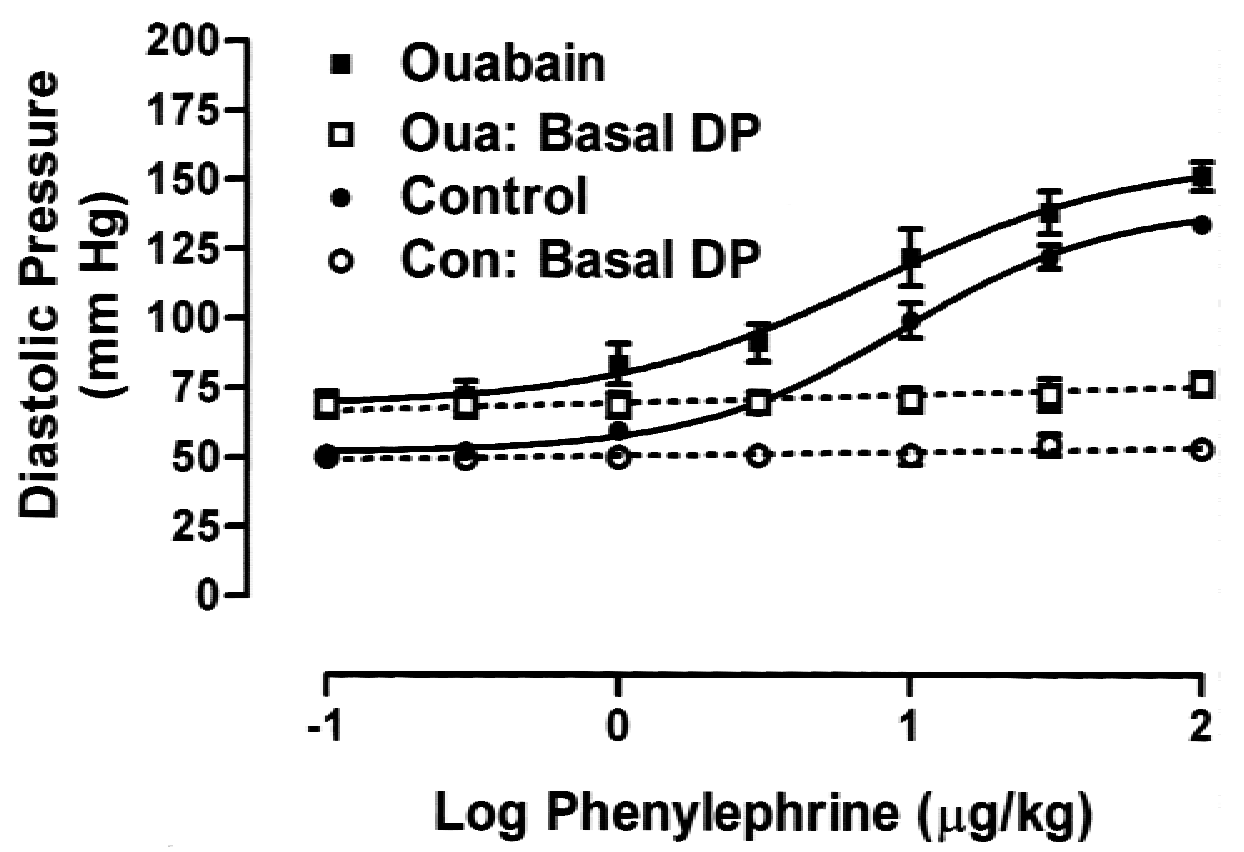

FIG. 2. Comparison of the pressor effects in control reflex-blocked and ouabain-treated (18 $\mu \mathrm{g} / \mathrm{kg}$, i.v.) animals. Data show the basal diastolic pressure (Basal DP) before administration of phenylephrine (open symbols) and the peak diastolic pressure obtained after the administration of phenylephrine (closed symbols) and are the mean \pm SEM for six animals in each group.

caused a significant ( $\mathrm{p}<0.005$, paired $t$ test) increase in the "basal" diastolic pressure of $18.8 \pm 3.2 \mathrm{~mm} \mathrm{Hg}$. However, as shown in Table 2, short-term administration of ouabain had no effect on either the sensitivity (log $\left.E_{50}\right)$ or the responsiveness $\left(E_{\max }\right)$ for phenylephrine.

Table 2 shows the dose-response parameters, log $\mathrm{ED}_{50}$, maximal change in diastolic pressure, and slope parameter, for phenylephrine in the various experimental groups. The $\log \mathrm{ED}_{50}$ values for phenylephrine in the L-NAME and angiotensin II groups were significantly

TABLE 2.

Dose-response parameters for vasopressor actions of phenylephrine ${ }^{a}$

\begin{tabular}{|c|c|c|c|c|}
\hline \multirow[b]{2}{*}{$\begin{array}{l}\text { Treatment } \\
\text { group }\end{array}$} & \multicolumn{4}{|c|}{ Parameter } \\
\hline & $\log \mathrm{ED}_{50}$ & $\begin{array}{l}\text { Maximum change } \\
\text { in diastolic } \\
\text { pressure }(\mathrm{mm} \mathrm{Hg})\end{array}$ & Slope factor & No. \\
\hline Control & $0.94 \pm 0.08$ & $87 \pm 1$ & $1.15 \pm 0.06$ & 6 \\
\hline Ouabain & $0.80 \pm 0.12$ & $83 \pm 2$ & $0.96 \pm 0.04$ & 6 \\
\hline L-NAME 3.0 & $0.10 \pm 0.04^{b}$ & $62 \pm 5^{*}$ & $0.83 \pm 0.06$ & 5 \\
\hline Angiotensin II & $0.51 \pm 0.10^{b}$ & $82 \pm 4$ & $1.13 \pm 0.10$ & 6 \\
\hline
\end{tabular}

${ }^{a}$ Values are mean \pm SEM for number of animals. Values for maximal response have been rounded to nearest whole number.

${ }^{b}$ Significantly different from the control value, $\mathrm{p}<0.05$, one-way ANOVA followed by a Dunnet's post hoc test. less than that of the control group (corresponding $\mathrm{ED}_{50}$ values are $1.3 \pm 1.0$ and $3.2 \pm 1.2 \mu \mathrm{g} / \mathrm{kg}$ vs. $8.7 \pm 1.2$ $\mu \mathrm{g} / \mathrm{kg}$, respectively), showing an increase in the potency of phenylephrine. The $\log \mathrm{ED}_{50}$ of phenylephrine in the ouabain group (the $\mathrm{ED}_{50}$ value was $6.3 \pm 1.3 \mu \mathrm{g} / \mathrm{kg}$ ) was not significantly different from that of the control group. The maximal change in diastolic pressure produced by phenylephrine was decreased in the L-NAME group. Although L-NAME, at this dose, reduced the maximal change in diastolic pressure produced by phenylephrine, there were no significant differences in the values for the actual diastolic pressures produced by phenylephrine among any of the experimental groups. None of the drug treatments altered the slope factor for the dose-response curves.

Ouabain at $6 \mu \mathrm{g} / \mathrm{kg}$, i.v., produced an $8 \pm 2 \mathrm{~mm} \mathrm{Hg}(\mathrm{p}$ $<0.05$, paired $t$ test) increase in the diastolic pressure. Figure 3 shows the increases in diastolic pressure produced by norepinephrine before and at 60-75 min after ouabain administration. After administration of ouabain, there were no significant effects on the responses to norepinephrine.

Figure 4 shows the effect of phentolamine on the pressor actions of ouabain. Panel A shows the effects of phentolamine on the established pressor response to of ouabain, panel B shows the effect of pretreatment with phentolamine, and panel $\mathrm{C}$ shows the increase in diastol- 


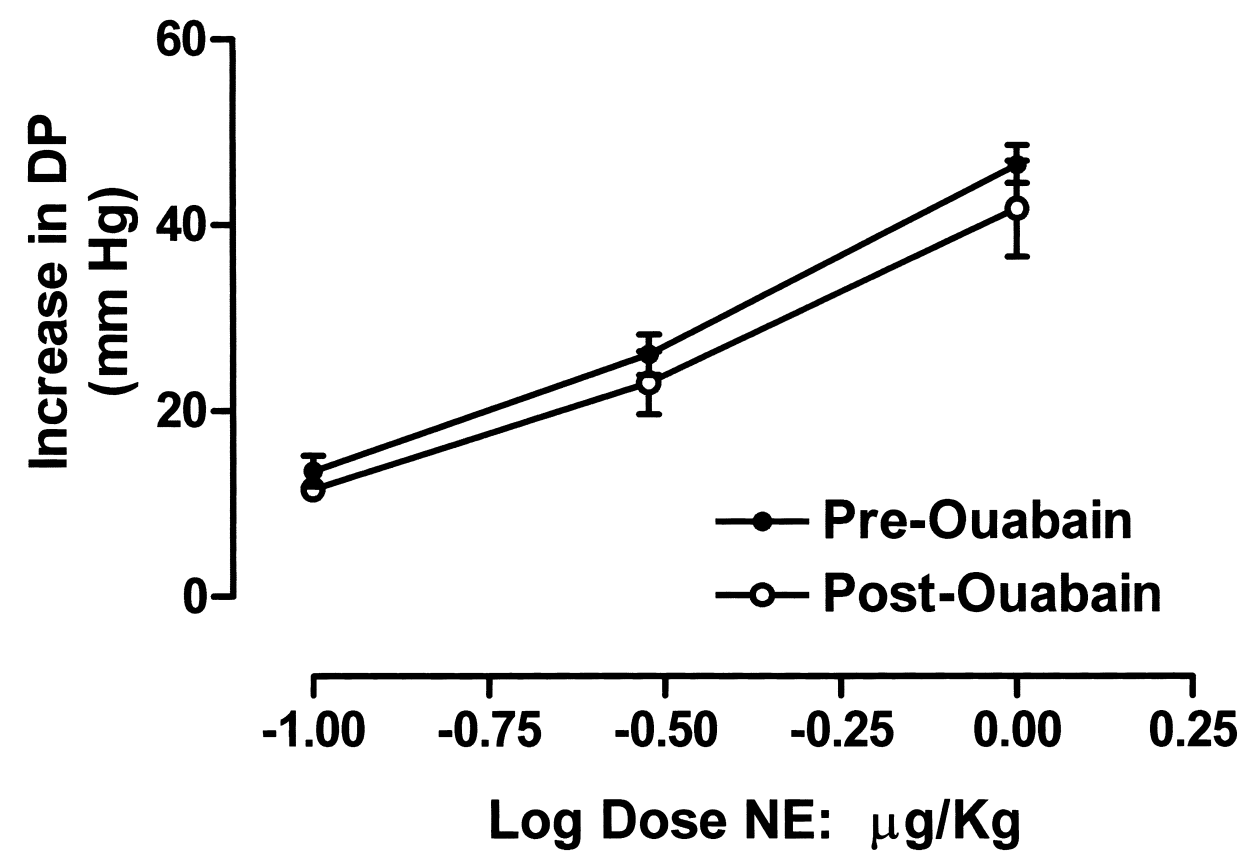

FIG. 3. Effect of ouabain on the pressor response to norepinephrine (NE). Data are the mean \pm SEM for four animals. Responses were obtained to norepinephrine before and at $60-75 \mathrm{~min}$ after the administration of ouabain $(6 \mu \mathrm{g} / \mathrm{kg})$. The diastolic pressure before and after the administration of ouabain was $60 \pm 3$ and $68 \pm 5 \mathrm{~mm} \mathrm{Hg}$. The increase was significant $(\mathrm{p}<0.05$, paired $t$ test). Ouabain did not alter the responses to submaximal doses of norepinephrine.

ic pressures produced by ouabain in the absence of phentolamine and in the presence of phentolamine. Pretreatment with phentolamine produced a small but significant decrease in diastolic pressure of $7.5 \pm 3 \mathrm{~mm} \mathrm{Hg}(\mathrm{p}<$ 0.05 , repeated measures one-way ANOVA followed by Tukey's post hoc test, $\mathrm{n}=6$ ). At $60 \mathrm{~min}$ after the subsequent administration of ouabain (70 min after phentolamine) there was a significant increase $(\mathrm{p}<0.01), 11 \pm$ $4 \mathrm{~mm} \mathrm{Hg}$, in the diastolic pressure relative to that following phentolamine administration. The resultant diastolic pressure was not significantly different from the control diastolic pressure before phentolamine administration ( $p>0.05$ ). When phentolamine was administered at the plateau of the pressor effect of ouabain, the change in diastolic pressure was reversed from an increase of 20 $\pm 2 \mathrm{~mm} \mathrm{Hg}$ to an increase of $8 \pm 3 \mathrm{~mm} \mathrm{Hg}$ above the pre-ouabain control diastolic pressure of $57 \pm 3 \mathrm{~mm} \mathrm{Hg}$. The increase in diastolic pressure produced by ouabain in absence of phentolamine, $20 \pm 2 \mathrm{~mm} \mathrm{Hg}$, was significantly different from that produced in the presence of phentolamine, $11 \pm 4 \mathrm{~mm} \mathrm{Hg}(\mathrm{p}<0.05)$. These results show that the pressor response to ouabain was both partially prevented and partially reversed by phentolamine.

Collectively, the results of the experiments with ouabain at $18 \mu \mathrm{g} / \mathrm{kg}$ show that it produced very similar increases in diastolic pressure of $18.8 \pm 3.2$ and $20.0 \pm$
$2.2 \mathrm{~mm} \mathrm{Hg}$. At a dose of $6 \mu \mathrm{g} / \mathrm{kg}$, the increase in diastolic pressure produced by ouabain, $8 \pm 2 \mathrm{~mm} \mathrm{Hg}$, was less than that produced by $18 \mu \mathrm{g} / \mathrm{kg}$, showing a doserelated effect of short-term administration of ouabain on blood pressure.

\section{DISCUSSION}

The results of the present study show that relatively low doses of ouabain, 6 and $18 \mu \mathrm{g} / \mathrm{kg}$, i.v., (approximately $10-30 \mathrm{nmol} / \mathrm{kg}$ ) cause dose-related increases in diastolic blood pressure in the anesthetized, reflexblocked rat. In rats, the latter dose and route of administration of ouabain has been shown to produce a peak plasma level of $40 \mathrm{n} M$ within $10 \mathrm{~min}$ that returns to preinjection levels by $2 \mathrm{~h}$, with increased urinary excretion of ouabain for $6 \mathrm{~h}$ after administration (26). The results of studies from this laboratory (Rossoni LV, Vassallo DV, unpublished observations) showed that this dose of ouabain produces an increase in mean arterial pressure that reaches a plateau in $1 \mathrm{~h}$ and is maintained for at least $1 \mathrm{~h}$. All of the observations made on the pressor responses to phenylephrine and norepinephrine were carried out during this time when the pressor response to ouabain was constant and under conditions of 

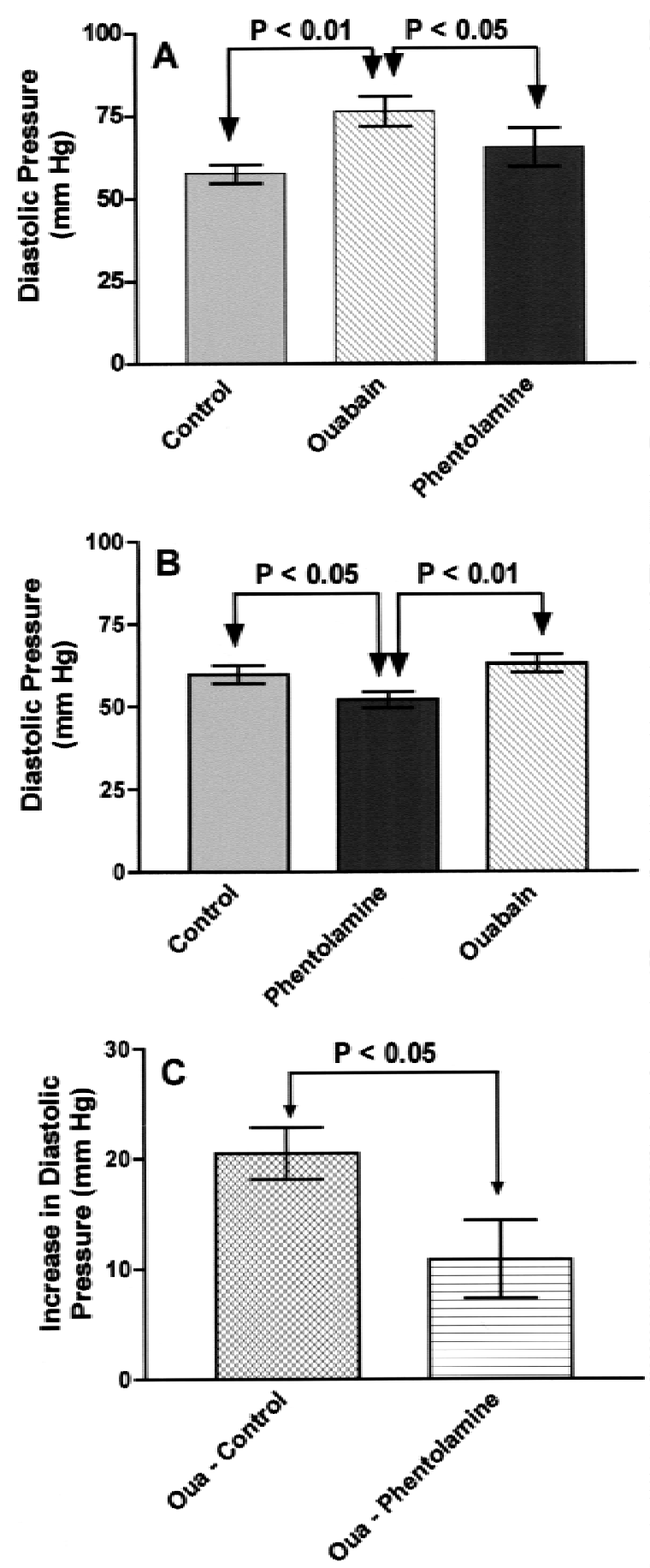

FIG. 4. Phentolamine partially reverses and partially prevents the pressor response produced by ouabain. Panel $\mathbf{A}$ shows the control diastolic pressure, the pressure 60 min after the administration of ouabain $(18 \mu \mathrm{g} / \mathrm{kg})$, and the pressure $10 \mathrm{~min}$ after the subsequent administration of phentolamine (3 mg/kg, i.v.). Panel B shows the control diastolic pressure, the pressure $10 \mathrm{~min}$ after the administration of phentolamine and the pressure $60 \mathrm{~min}$ after the subsequent administration of ouabain. Panel $\mathbf{C}$ shows the increase in diastolic pressure produced by ouabain (Oua) relative to control diastolic pressure (from panel $\mathbf{A}$ ) and the increase relative to the diastolic pressure after phentolamine (from panel B). Data are the mean \pm SEM for six animals per group. reflex blockade. Under these conditions, changes in diastolic pressure should reflect direct actions on the vasculature that are not modulated by autonomic reflexes. Importantly, we observed that in reflex-blocked rats, baroreceptor-mediated decreases in pulse rate were largely abolished to the same extent $-100 \%-87 \%$ depending on the dose of phenylephrine-in control and ouabain-treated rats. This observation shows that the blockade was effective and that reflexes did not unduly influence the dose-response curves for the pressor actions of phenylephrine. Because we wished to avoid potential effects of ouabain on baroceptor reflexes (27-29) that might interfere with the short-term pressor effects of phenylephrine, we did not study the effects of ouabain on phenylephrine in animals with intact reflexes.

Because reflexes were blocked, we conclude that the short-term pressor effects of ouabain were peripheral in origin and not related to its direct central nervous system actions $(8,27)$ or its actions at sensory afferent nerve endings (28-30). The results of our experiments with phentolamine suggest that in the present study the pressor actions of ouabain were mediated indirectly by norepinephrine released from sympathetic nerves as well as by a direct action on vascular smooth muscle cells. Presumably, both actions were due to the inhibition of $\mathrm{Na}^{+}, \mathrm{K}^{+}$-ATPase. Indirect and direct contractile actions of ouabain have been reported (6,31-33). Low micromolar concentrations of ouabain and acetylstrophanthidin potentiated the vasomotor response to adrenergic nerve stimulation in canine isolated arteries and veins under conditions in which the direct contractile actions of norepinephrine were unaltered and those of a selective $\alpha_{2}{ }^{-}$ agonist only slightly enhanced $(32,33)$. In human volunteers, the short-term in vivo vasoconstrictor responses to doses of ouabain similar to those used in the present study were not altered by pretreatment with guanethidine (6). In the rat, both mechanisms appear to be operative.

The potency, $\mathrm{ED}_{50}$, of phenylephrine to increase diastolic pressure found in the present study, $8.7 \mu \mathrm{g} / \mathrm{kg}$, agrees fairly well with values of 6-7 $\mu \mathrm{g} / \mathrm{kg}$ reported in the literature $(34,35)$. Also in agreement with the literature, we find that L-NAME and angiotensin II can increase the potency of phenylephrine $(22,23)$. Because there were no significant differences among the maximal diastolic pressure produced by phenylephrine in any of the treatment groups, the effects of the higher doses of L-NAME on the maximal change in diastolic pressure produced by phenylephrine were most likely caused by the pressor effect of L-NAME, which imposed a lower limit on the maximal change that could be obtained. In contrast to the results obtained with L-NAME and angiotensin II, ouabain elevated the base-line diastolic pres- 
sure but did not alter the ability of phenylephrine to produce an increase in diastolic pressure. Because the baseline was elevated, the resultant diastolic pressure was higher, but the increment above baseline produced by phenylephrine was not altered. Relative to the control group, neither the potency nor the maximal response of phenylephrine was altered in the group treated short term with this dose of ouabain. Similarly, we found that ouabain did not alter the responsiveness to norepinephrine. We evaluated the effects of a lower dose of ouabain on the pressor actions of three submaximal doses of norepinephrine in the same animals before and after the administration of ouabain and found no changes in the response. Under the conditions used here, ouabain did not sensitize the vasculature to the actions of phenylephrine or norepinephrine. Instead, our results show that the pressor effects of ouabain and these $\alpha$-adrenoceptor agonists were simply additive.

In view of the previous reports that cardiac glycosides enhance the actions of pressor agents $(20,36)$, the present observations were unexpected. However, in many of the these studies, full dose-response curves for vasoconstrictors, norepinephrine and angiotensin or phenylephrine, were not generated, so it is difficult to determine if the treatments produced an increase in responsiveness or an increase in the potency of the agonist, or both. In one study in which several doses of norepinephrine and angiotensin II were used, it was observed that short-term treatment with digoxin increased the ability of these agents to increase mean arterial pressure (36). Interestingly, these data show that this was due to increases in systolic pressure responses and not diastolic pressure responses.

In studies that showed that nanomolar concentrations of ouabain produced a slight enhancement of caffeineevoked contraction of isolated vascular preparations and that ouabain enhanced the ability of phenylephrine to enhance the actions of caffeine (21), no results were reported on the direct interactions between ouabain and phenylephrine. The results of other studies using rat isolated thoracic aorta preparations show that ouabain at concentrations of less than $10 \mu M$ had no contractile actions and no effect on concentration-response curves for phenylephrine $(37,38)$. Ouabain at $100 \mu M$ increased the maximal response to phenylephrine without altering the potency of phenylephrine in aorta from one-kidney, one-clip renal hypertensive rats and had no effect on the actions of phenylephrine on aorta from one-kidney nonhypertensive rats (38). Previous studies from this laboratory showed that $100 \mu M$ ouabain enhanced the actions of phenylephrine in the rat isolated tail vascular bed preparation (39) and suggested that $10 \mathrm{n} M$ ouabain also increased the responsiveness to phenylephrine (7). In the latter studies, only a limited dose range that corresponds to the lower portion of a dose-response curve for phenylephrine was used. The results of more recent studies (40) with the rat perfused isolated tail vascular bed preparation in which full dose-response curves for the change in perfusion pressure produced by phenylephrine showed that $10 \mathrm{n} M$ ouabain had no effect on the potency of phenylephrine and produced a small increase in the estimated maximal response.

In contrast, the enhancing effects of ouabain and acetylstrophanthidin on the vascular response to adrenergic nerve stimulation are readily seen at concentrations of less than $10 \mu M(32,33)$. It is also of interest to note that low micromolar concentrations of ouabain and dihydroouabain have been shown to enhance the actions of serotonin on rabbit isolated ear arteries by a $\mathrm{Na}^{+}, \mathrm{K}^{+}$ATPase-independent mechanism $(41,42)$.

It could be argued that the use of anesthetized animals precluded the demonstration of an ouabain-enhanced sensitivity and responsiveness to phenylephrine and norepinephrine. However, the results of the experiments with the short-term administration of L-NAME and angiotensin II clearly show that the measuring system used can be manipulated to cause an increase in the potency of phenylephrine and that this can occur in the absence of any measurable changes in diastolic pressure. Additionally, the effects of ouabain on afferent baroreceptor nerve activity are readily demonstrable in rats anesthetized with urethane $(29,30)$. Although it does seem likely that there was an interference with the anesthetic, experiments in wake animals are required to fully evaluate this possibility.

The results of the present study do not support the notion that nanomolar concentrations of ouabain enhance the actions of vasoconstrictor agents in anesthetized rats. Although the present study has the limitation of only addressing the short-term actions of ouabain in anesthetized animals, the results of recently published experiments on the effects of long-term administration of ouabain show that the potency and maximal response of phenylephrine is reduced in some isolated vascular preparations $(5,43)$. It would seem that the role of endogenous ouabain in hypertension is not that of simply amplifying contractile actions.

Acknowledgment: This study was supported by grants from Conselho Nacional de Desenvolvimento Cientifico e Tecnológico (CNPq) and Coordenação de Aperfeiçoamento de Pessoal de Nivel Superior-CAPES. The authors wish to thank Dr. Ivanita Stefanon, Dr. Valber Dias Pinto, and Silvio Preti for their assistance in 
performing the surgeries and Dr. Emel Songu-Mize for her helpful suggestions.

\section{REFERENCES}

1. Blaustein MP. Endogenous ouabain: role in the pathogenesis of hypertension. Kidney Int 1996;49:1748-53.

2. Rossi GP, Manunta P, Hamlyn JM, et al. Immunoreactive endogenous ouabain in primary aldosteronism and essential hypertension: relationship with plasma renin, aldosterone and blood pressure levels. J Hypertens 1995; 13: 1181-91.

3. Pamnani MB, Chen S, Brynat JH, et al. Effects of three sodium-potassium adenosine triphosphatase inhibitors. Hypertension 1991;18:316-24.

4. Manunta P, Rogowski AC, Hamilton BP, et al. Ouabaininduced hypertension in the rat: relationships among circulating and tissue ouabain and blood pressure. J Hypertens. 1994;12:549-60.

5. Rossoni LV, Lores A, Salaices M, et al. Alterations on vascular reactivity and $\mathrm{Na}^{+} \mathrm{K}^{+}$ATPase in hypertension induced by chronic administration of ouabain. Annals of the XVI Latinamerican Congress of Pharmacology and VII Interamerican Congress of Clinical Pharmacology and Therapeutics. 2000, abstract 02.021, page 124 .

6. Manson, DT, Braunwald E. Studies on digitalis. X. Effects of ouabain on forearm vascular resistance and venous tone in normal subjects and in patients with heart failure. $J$ Clin Invest 1964;343:532-43.

7. Vassalo DV, Songu-Mize E, Rossoni LV, et al. Effects of ouabain on vascular reactivity. Braz J Med Biol Res 1997; 30:545-52.

8. Veerasingham SJ, Leenen FH. Ouabain- and central sodium-induced hypertension depend on the ventral anteroventral third ventricle region. Am J Physiol 1999;276: H63-70.

9. Sweadner KJ. Two molecular forms of $\left(\mathrm{Na}^{+}-\mathrm{K}^{+}\right)$stimulated ATPase in brain. Separation and difference in affinity for strophanthidin. J Biol Chem 1979;254:6060-7.

10. Shull GE, Green J, Lingrel JB. Molecular cloning of three distinct isoforms of the $\mathrm{Na}^{+}, \mathrm{K}^{+}$-ATPase $\alpha$ subunit from rat brain. Biochemistry 1986;25:8125-32.

11. Shamraj OL, Lingrel JB. Putative fourth $\mathrm{Na}^{+}, \mathrm{K}^{+}$-ATPase $\alpha$ subunit gene is expressed in testis. Proc Natl Acad Sci U S A 1194;91:12952-6.

12. Blanco G, Mercer RW. Isozymes of the $\mathrm{Na}^{+}, \mathrm{K}^{+}$-ATPase: heterogeneity in structure, diversity in function. Am J Physiol 1998;275:F633-50.

13. O'Brein WJ, Lingred JB, Wallick ET. Ouabain binding kinetics of the rat alpha two and alpha three isoforms of the sodium-potassium adenosine triphosphatase. Arch Biochem Biophys 1994;310:32-9.

14. Kolansky DM, Brines ML, Gilmore-Herbert M, et al. The $\alpha_{2}$ isoform of rat $\mathrm{Na}^{+}, \mathrm{K}^{+}$-adenosine triphosphatase is active and exhibits high ouabain affinity when expressed in transfected fibroblasts FEBS Lett 1992;303:147-53.

15. Sahin-Erdemli I, Rashed S, Songu-Mize E. Rat vascular tissues express all three alpha-isoforms of $\mathrm{Na}^{+}, \mathrm{K}^{+}$ATPase. Am J Physiol 1994;266:H350-3.

16. Golovina VA, Blaustein MP. Spatial and functionally dis- tinct $\mathrm{Ca}^{+2}$ stores in sarcoplasmic and endoplasmic reticulum. Science 1997;275:1643-8.

17. Juhaszova M, Blaustein MP. $\mathrm{Na}^{+}$pump low and high affinity ouabain affinity alpha subunit isoforms are differently distributed in cells. Proc Natl Acad Sci U S A 1997; 94:1800-5.

18. Zhu Z, Tepel M, Neusser M, et al. Low concentrations of ouabain increase cytosolic free calcium concentrations in rat vascular smooth muscle cells. Clin Sci (Colch) 1996; 90:9-12.

19. Blaustein MP, Juhaszova M, Golovina VA. The cellular mechanism of action of cardiotonic steroids: a new hypothesis. Clin Exp Hypertens 1998;20:691-703.

20. Yamaji I, Kikuchi K, Nishimura M, et al. The role of $\mathrm{Na}, \mathrm{K}-\mathrm{ATPase}$ inhibitor on presor responsiviness in patients with benign essential hypertension. Am J Hypertens 1990;3:176-81.

21. Weiss, DN, Podberesky DJ, Heidrich J, et al. Nanomolar ouabain augments caffeine-evoked contractions in rat arteries. Am J Physiol 1993;265:C1443-8.

22. Chyu KY, Guth PH, Ross G. Effects of $N$-omega-nitro-Larginine methylester on arterial pressure and vasoconstrictor responses. Influence of initial vascular tone. Eur $J$ Pharmacol 1992;212:159-64.

23. Uemura N, Vatner DE, Shen YT, et al. Increased alpha 1-adrenergic vascular sensitivity during development of hypertension in conscious dogs. Am J Physiol 1993;264: H1259-68.

24. Dowell FJ, Henrion D, Benessiano J, et al. Chronic infusion of low-dose angiotensin II potentiates the adrenergic response in vivo. J Hypertens 1996;14:177-82.

25. Finney DJ. Statistical method in biological assay. New York: Hafner Publishing Company, 1952: 67.

26. Yuan CM, Manunta P, Hamlyn JM, et al. Long-term ouabain administration produces hypertension in rats. Hypertension 1993;22:178-87.

27. Caldwell RW, Songu-Mize E, Bealer SL. The vasopressor response to centrally administered ouabain. Circ Res 1984; 55:773-9.

28. Quest JA, Gillis RA. Effect of digitalis on carotid sinus baroreceptor activity. Circ Res 1974;35:247-255.

29. Abreu GR, Futuro Neto HA, Cabral AM, et al. Ouabain produces diverse excitatory effects on afferent baroreceptor nerve activity in SHR and WKY animals. Clin Exp Hypertens 1998;20:85-94.

30. Abreu GR, Futuro-Neto H, Cabral AM, et al. L-Arginine restores the effect of ouabain on baroreceptor activity and prevents hypertension. Hypertension 1999;34:729-32.

31. Woolfson RG, Hilton PJ, Poston L. Effects of ouabain and low sodium on contractility of human resistance arteries. Hypertension 1990;15:583-90.

32. Brender D, Vanhoutte PM, Shepherd JT. Potentiation of adrenergic venomotor responses in dogs by cardiac glycosides. Circ Res 1969;25:597-606.

33. Aarhus LL, Shepherd JT, Tyce GM, et al. Contractions of canine vascular smooth muscle cells caused by ouabain are due to release of norepinephrine from adrenergic nerve endings. Circ Res 1983;52:274-82.

34. Guilmard C, Auguet M, Chabrier PE. Pharmacological characterization of the alpha 1-adrenoceptor subtype mediating regulation of arterial pressure and urethral perfu- 
sion pressure in the anesthetized rat. J Auton Pharmacol 1996;16:197-303.

35. Minami N, Imai Y, Nishiyama $H$, et al. Role of nitric oxide in the development of vascular alpha 1-adrenoceptor desensitization and pressure diuresis in conscious rats. $\mathrm{Hy}$ pertension 1997;29:969-75.

36. Guthrie Jr GP. Effects of digoxin on responsiveness to pressor actions of angiotensin and norepinephrine in man. J Clin Endocr Metab 1984;58:76-80.

37. Bagrov AY, Roukoyatkina NI, Pinaev AG, et al. Effects of two endogenous $\mathrm{Na}^{+}, \mathrm{K}^{+}$-ATPase inhibitors, marinobufagenin and ouabain, on isolated rat aorta. Eur J Pharmacol 1995;274:151-8.

38. Ceron PIB, Bendhack LM. Increased contractile response induced with ouabain is abolished by thapsigargin in aorta of renal hypertensive rats. Gen Pharmacol 1997;29:67-72.

39. Songu-Mize E, Vassallo DV, Rashed SM, et al. Ouabain amplifies contractile responses to phenylephrine in rat tail arteries in hypertension. J Basic Clin Physiol Pharmacol 1995;6:309-19.

40. Davel AP, Rossoni LV, Vassallo DV. Effects of ouabain on the pressor response to phenylephrine and on the functional activity of the sodium pump in streptozotocininduced diabetic rats [abstract 88]. Hypertension 1999;33: 1073.

41. Xu Z, Song JP, Purdy RE. Effect of ouabain on the rabbit ear artery contraction to serotonin; enhanced response mediated by serotonergic rather than alpha adrenergic receptors. J Pharmacol Exp Ther 1990;253:668-75.

42. Purdy RE, Prins BA, Weber MA, et al. Possible novel action of ouabain: allosteric modulation of vascular serotonergic $\left(5-\mathrm{HT}_{2}\right)$ and angiotensin $\left(\mathrm{AT}_{1}\right)$ receptors. $J$ Pharmacol Exp Ther 1993;267:228-37.

43. Cargnelli G, Trevisi L, Debetto P, et al. Effect of long-term ouabain treatment on contractile responses of rat aortae. $J$ Cardiovasc Pharmacol 2000;35:538-42. 